
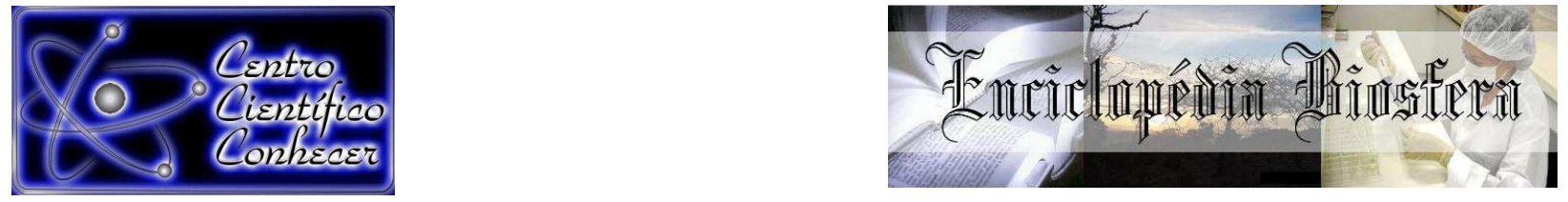

\title{
O CEARÁ É TOTALMENTE CIRCUNSCRITO À CAATINGA? O QUE DIZEM OS LIVROS DIDÁTICOS E OS PROFESSORES DO ENSINO MÉDIO?
}

\author{
Maria da Conceição Valentim Eufrásio ${ }^{1}$; Andréa Pereira Silveira $^{2^{*}}$
}

1 Licenciada em Ciências Biológicas pela Universidade Estadual do Ceará, Campus da Faculdade de Educação de Itapipoca (UECE/FACEDI) Itapipoca-Ceará-Brasil.

2 Professora Adjunta do Curso de Licenciatura em Ciências Biológicas da Universidade Estadual do Ceará, Campus da Faculdade de Educação de Itapipoca

(UECE/FACEDI) Itapipoca-Ceará-Brasil, andrea.silveira@uece.br

Recebido em: 02/10/2017 - Aprovado em: 21/11/2017 - Publicado em: 05/12/2017 DOI: 10.18677/EnciBio_2017B101

\begin{abstract}
RESUMO
O Ceará é representado nos mapas nacionais, como totalmente circunscrito à Caatinga. No entanto, o seu território abriga oito tipos de vegetação. Diante desse paradoxo, delineou-se o objetivo de averiguar quais vegetações cearenses são abordadas nos livros didáticos (LDs) do ensino médio e o modo como os professores trabalham essa temática. Foram analisadas oito coleções de Biologia e Geografia (universo de 24 LDs), adotadas por quatro escolas públicas de ItapipocaCeará. Um total de 11 dos 19 professores que lecionam Biologia e Geografia, responderam sobre quais tipos de vegetação cearense ensinam, além de estratégias e recursos utilizados. Dentre os oito tipos de vegetação cearense, apenas cinco estão presentes nos livros de Biologia (Caatinga, Cerrado, Mangue, Vegetação Litorânea e Carnaubal) e seis nos livros de Geografia (Caatinga, Cerrado, Mangue, Vegetação Litorânea, Carnaubal e Mata Úmida), mas na maioria dos LDs analisados, as vegetações são descritas sem referência clara a sua ocorrência no Ceará, com exceção da Ćaatinga. Os livros de Biologia não contemplam o Carrasco, a Mata Seca e a Mata Úmida, e os de Geografia não consideram o Carrasco e a Mata Seca. De modo semelhante, os professores trabalhavam a vegetação de Caatinga em suas aulas, mas não ensinavam sobre Cerrado, Carrasco e Mata Seca. A abordagem centrada na vegetação de Caatinga tanto nos LDs quanto na prática docente, a despeito da diversidade paisagística do estado do Ceará, pode contribuir para a falsa imagem de pobreza paisagística e de biodiversidade, que são associadas à região nordeste.
\end{abstract}

PALAVRAS-CHAVE: bioma, semiárido, vegetação.

\section{IS CEARA TOTALLY CONFINED TO CAATINGA? WHAT THE BOOKS AND TEACHING PRACTICE SAYS IN MIDDLE SCHOOL}

\begin{abstract}
The Ceara is represented in the national maps, as totally occupied by Caatinga. However, its territory harbors eight types of vegetation. In view of this paradox, the objective this of knowing which Ceara vegetation is addressed in high school books (SBs) and how teachers work on this topic was delineated. Eight collections of
\end{abstract}


Biology and Geography (24 SBs) were analyzed, which are adopted by four public schools in Itapipoca-Ceara. A total of 11 of the 19 teachers who taught Biology and Geography, answered on what types of vegetation of Ceara teach, in addition to strategies and resources used. Of the eight vegetation types, only five are present in the Biology books (Caatinga, Cerrado, Mangrove, Coastal Vegetation and Carnauba Forest) and six in the books of Geography (Caatinga, Cerrado, Mangrove, Coastal Vegetation, Carnauba Forest and Ombrophilous Montane Forest), but in most LDs analyzed, the vegetation is described without clear reference to its occurrence in Ceara, with the exception of the Caatinga. The Biology books do not contemplate the Carrasco, Dry Forest and Ombrophilous Montane Forest vegetation, and those of Geography do not consider Carrasco and Dry Forest vegetation. Similarly, teachers worked the vegetation of the Caatinga in their classes, but did not teach about Cerrado, Carrasco and Mata Dry Forest. The focus on Caatinga vegetation in both SB and teaching practice, in spite of the landscape diversity of the state of Ceara, can contribute to the false image of landscape poverty and biodiversity, which are associated with the northeast region.

KEYWORDS: biome, semiarid, vegetation.

\section{INTRODUÇÃo}

O Estado do Ceará está localizado na região nordeste do Brasil e possui a maior parte do território sob clima semiárido quente com chuvas de verão e inverno secos - BSh de Köppen-Geiger (IPECE, 2007). No entanto, no Ceará ocorrem também áreas de climas mais amenos, como aqueles registrados nas serras, chapadas e próximo ao litoral (IPECE, 2007). Essa variedade climática, associada à variabilidade geomorfológica e aos diferentes tipos de solos, resulta em diferentes tipos de vegetação, denominadas de unidades fitoecológicas no mapa de vegetação do estado (FIGUEIREDO, 1997).

Embora a cobertura vegetal do Ceará seja dominada pela Caatinga, existem outras vegetações ocupando menor extensão territorial como a Mata Seca, a Mata Úmida e o Carrasco que ocorrem nas serras e chapadas (ARAÚJO et al., 2005). A Caatinga não predomina apenas no Ceará, mas também em toda a região Nordeste do Brasil. Esta cobre uma área de aproximadamente $734.478 \mathrm{~km}^{2}$, o que representa $70 \%$ da região Nordeste e $11 \%$ do território nacional, distribuídos nos estados do Piauí, Ceará, Rio Grande do Norte, Paraíba, Pernambuco, Alagoas, Sergipe e Bahia, além de uma área no norte de Minas Gerais (IBGE, 2004).

Apesar da diversidade paisagística do Brasil, as vegetações são apresentadas de forma bastante simplificada nos mapas nacionais. O Brasil é comumente representado por apenas seis vegetações ("biomas" sensu IBGE, 2004), e o Ceará, a despeito da diversidade de relevos, paisagens e vegetações, aparece completamente circunscrito à Caatinga. Se por um lado, essa divisão simplificada facilita o planejamento de políticas públicas, por outro lado, obscurece o fato de que em cada região ocorrem diferentes tipos de vegetação (MORO et al., 2015). Além disso, essa simplificação na representação da vegetação pode contribuir para a perpetuação da falsa ideia de que o nordeste brasileiro é pobre em diversidade biológica (ARAÚJO et al., 2005; MORO et al., 2014).

Contudo, a heterogeneidade vegetacional do Ceará é evidenciada em mapas em escala local baseados em atributos fisionômicos (FIGUEIREDO, 1997), ou predominantemente florísticos (MORO et al., 2015). Adotou-se a classificação fisionômica de Figueiredo (1997), primeiro porque esta é mais adequada para efeitos 
comparativos e segundo porque a proposta de Moro et al. (2015) é recente e seguramente não foi incorporada nos livros didáticos (LD).

A classificação de Figueiredo (1997) divide o Ceará em oito vegetações, denominadas de Unidades Fitoecológicas que são: 1) Complexo Vegetacional da Zona Litorânea (Vegetação litorânea-CVL), 2) Floresta Subperenifólia Tropical Plúvio-Nebular (Mata Úmidas Serranas-MUS), 3) Floresta Subcaducifólia Tropical Pluvial (Mata Seca-MS); 4) Vegetação Caducifólia Espinhosa (Caatinga, subdivididas em Caatinga Arbórea-CA, Caatinga Arbustiva Densa-CAD e Caatinga Arbustiva Aberta-CAA); 5) Vegetação Caducifólia não Espinhosa (Carrasco-CRR); 6) Floresta Perenifólia Paludosa Marítima (Mangue-MAN); 7) Floresta Mista Dicotillo Palmácea (Mata Ciliar com carnaúba e dicotiledôneas-MCC) e 8) Floresta Subcaducifólia Tropical Xeromorfa (Cerradão-CED) e Cerrado (CER).

A simplificação da vegetação representada nos documentos e mapas governamentais, a despeito da heterogeneidade existente, suscitaram as questões norteadoras desta investigação que consistem em saber se: i) os diferentes tipos de vegetação cearense são abordados nos livros didáticos de nível médio? ii) quando os diferentes tipos de vegetação do estado do Ceará são abordados, de que modo eles são retratados pelos autores? iii) os professores ensinam sobre os diferentes tipos de vegetação do estado do Ceará em escolas de ensino médio cearense?

Não se sabe se a Caatinga é o único tipo de vegetação cearense abordado nos LDs, mas é sabido que o LD é o recurso mais utilizado no ensino básico (MATOS; LANDIM, 2014). Se por um lado as pesquisas apontam que os professores não devem se deter ao conteúdo dos livros didáticos, por outro lado, este ainda é o principal instrumento pedagógico para a maioria dos professores (BEZERRA; SUESS, 2013). Diante desse contexto, foram delineados os seguintes objetivos: i) examinar o conteúdo presente nos livros didáticos de Biologia e Geografia, adotados por quatro escolas públicas estaduais da sede do município de Itapipoca-Ceará e ii) investigar se e como os professores abordam os tipos de vegetação cearense, bem como as fontes de informações e os recursos utilizados.

\section{MATERIAL E MÉTODOS}

A pesquisa foi de caráter qualitativo, pois o pesquisador mantém contato direto com o ambiente, o sujeito e o objeto de estudo, e as questões são estudadas sem manipulações intencional do pesquisador e sem tratamentos estatísticos dos dados obtidos (PRODANOV; FREITAS, 2013). A pesquisa foi desenvolvida em duas etapas: 1) consistiu na análise do conteúdo presente nos livros didáticos (LDs) de Biologia e Geografia, utilizados por quatro escolas estaduais da rede pública de Itapipoca-Ceará; 2) consistiu em examinar se e como os professores abordam os tipos de vegetação cearense na prática pedagógica, além de buscar saber quais são as fontes de informação e os recursos utilizados.

Foi utilizada a técnica de análise de conteúdo de Bardin, tanto na análise do conteúdo dos LDs quanto na pesquisa com os professores. Segundo Bardin (2011), a análise de conteúdo organiza-se em três eixos: 1) a pré-análise; 2) a exploração do material e 3) o tratamento dos resultados, a inferência e a interpretação. Durante a pré-análise, foi utilizada a leitura flutuante para detectar o material que seria utilizado. A partir daí deu-se início a exploração do material, que consistiu essencialmente de operações de codificação, desconto ou enumeração, em função de atributos previamente formulados. Em seguida ocorreram as etapas de tratamento, interpretação e divulgação dos resultados. 


\section{Análise dos livros didáticos (LD)}

A escolha dos livros de Biologia e Geografia deveu-se ao fato de que estes são os livros que comumente abordam a temática relacionada aos tipos de vegetação. Foram selecionados os livros de $1^{\circ}, 2^{\circ}$ e $3^{\circ}$ ano, pois não se tinha 0 conhecimento prévio de em quais volumes seriam abordados a temática da pesquisa, uma vez que dependendo da coleção o mesmo conteúdo pode ser tratado em séries distintas. Para saber se e como os tipos de vegetação do estado do Ceará são abordados nos livros didáticos selecionados, inicialmente foi realizada uma leitura exploratória (leitura flutuante) das 24 obras alvo do estudo, com o intuito de detectar em quais capítulos a temática era tratada. Foi utilizado um roteiro de análise com base nos critérios de Matos e Landim (2014) e Santos et al. (2015). Foram atribuídas de 1 a $4(1=$ fraco, $2=$ regular, 3 = bom, $4=$ excelente $)$ aos critérios estabelecidos nos eixos, conteúdo teórico e recursos visuais.

As coleções analisadas foram aprovadas pelo Ministério da Educação - MEC, através do Programa Nacional do Livro Didático para o Ensino Médio - PNLD (BRASIL, 2015). Portanto, o intuito da pesquisa não foi julgar se o livro deveria ou não estar em circulação, mas sim verificar o conteúdo apresentado e como a temática foi abordada.

\section{Análise da prática dos professores}

Para saber se e como os professores ensinam sobre os diferentes tipos de vegetação do estado do Ceará, independente desta temática estar presente nos livros didáticos, foi utilizado um questionário como instrumento de coleta de dados. Dentre as vantagens deste instrumento, destaca-se o custo reduzido e o fato de permitir alcançar rápida e simultaneamente um grande número de pessoas (FARIAS et al., 2010). O questionário foi constituído das seguintes perguntas: Quais tipos de vegetação do estado do Ceará você aborda em suas aulas? Quais recursos e estratégias você utiliza? As demais perguntas eram para identificação, tais como escola em que trabalhou durante o ano de 2015, formação na graduação e/ou pósgraduação, e disciplina e turmas em que lecionou.

O questionário foi respondido pelos professores responsáveis pelas disciplinas de Biologia (14 professores) e Geografia (14 professores) das quatro escolas selecionadas que aceitaram participar da pesquisa e assinaram o termo de consentimento livre e esclarecido (TCLE), tendo sido reservado aos informantes o direito de desistência em qualquer momento da pesquisa, bem como o seu anonimato, como recomendado pela resolução 510/96 do Conselho Nacional de Saúde (BRASIL, 2016). O questionário foi aplicado presencialmente, entre os meses de janeiro a fevereiro de 2016, após o término do ano letivo de 2015. Dessa forma, foi garantido o andamento do ano letivo e a abordagem dos conteúdos sem a interferência dos pesquisadores.

\section{RESULTADOS E DISCUSSÃO}

O levantamento nas quatro escolas revelou um total de 28 professores e 24 livros didáticos (LD) pertencentes a oito coleções didáticas (CLD), com três volumes cada (Quadro 1). Com a leitura flutuante foi identificado que 13 LD pertencentes a oito CLD abordam direta ou indiretamente o tema tipos de vegetação, nestes chamados de "Biomas do Brasil", "Domínios Morfoclimáticos", "Domínios do Brasil", "Ecossistemas terrestres", ou "Formações vegetais" (Quadro 1). Foram analisados detalhadamente os 13 LD das oito CLD que abordam a temática pesquisada. 


\section{Livros de Biologia}

Do universo de 12 livros de Biologia, apenas oito abordavam o tema com alguma característica considerada relevante sobre o contexto da vegetação do Ceará. Dentre as coleções de Biologia a CDL 3 e a CDL 4 foram as que destinaram o maior espaço para o tema, e dentre as coleções de Geografia a CLD 5 foi a que designou maior espaço (Quadro 1).

QUADRO 1. Número de Professores e relação dos livros adotados pelas escolas estaduais de Itapipoca-Ceará, ano de 2015. Em negrito os volumes que abordam o assunto "vegetações brasileiras".

\begin{tabular}{|c|c|c|}
\hline Professor & Coleções e Volumes Biologia & Coleções e Volumes Geografia \\
\hline $\begin{array}{l}3 \text { Biologia } \\
4 \text { Geografia }\end{array}$ & $\begin{array}{l}\text { CLD1 }(\mathrm{VI}, \mathrm{VII}, \mathrm{VIII}) \\
\text { n. páginas }=3 ; 6 \text { relacionadas } \\
\text { n. figuras }=3 ; 4 \text { relacionadas }\end{array}$ & $\begin{array}{l}\text { CLD5 }(\mathrm{VI}, \mathrm{VII}, \mathrm{VIIII}) \\
\text { n. páginas }=13 ; 3 \text { relacionadas } \\
\text { n. figuras }=17 ; 4 \text { relacionadas }\end{array}$ \\
\hline $\begin{array}{l}4 \text { Biologia } \\
4 \text { Geografia }\end{array}$ & $\begin{array}{l}\text { CLD2 (VI, VII, VIII) } \\
\text { n. páginas }=5 ; 1 \text { relacionadas } \\
\text { n. figuras }=6\end{array}$ & $\begin{array}{l}\text { CLD6 (VI, VII, VIII) } \\
\text { n. páginas }=4 ; 1 \text { relacionadas } \\
\text { n. figuras }=3 ; 1 \text { relacionadas }\end{array}$ \\
\hline $\begin{array}{l}5 \text { Biologia } \\
5 \text { Geografia }\end{array}$ & $\begin{array}{l}\text { CLD3 (VI, VII, VIII) } \\
\text { n. páginas }=7 ; 7 \text { relacionadas } \\
\text { n. figuras }=16 ; 5 \text { relacionadas }\end{array}$ & $\begin{array}{l}\text { CLD7 }(\mathbf{V I}, \mathbf{V I I}, \mathrm{III}) \\
\text { n. páginas }=5 ; 4 \text { relacionadas } \\
\text { n. figuras }=2 ; 1 \text { relacionadas }\end{array}$ \\
\hline $\begin{array}{l}2 \text { Biologia } \\
1 \text { Geografia }\end{array}$ & $\begin{array}{l}\text { CLD4 }(\mathrm{VI}, \mathrm{VII}, \mathrm{III}) \\
\text { n. páginas }=8 ; 6 \text { relacionadas } \\
\text { n. figuras }=7 ; 6 \text { relacionadas }\end{array}$ & $\begin{array}{l}\text { CLD8 }(\mathrm{VI}, \mathrm{VII}, \mathrm{VIII}) \\
\text { n. páginas }=3 ; 1 \text { relacionadas } \\
\text { n. figuras }=3 ; 1 \text { relacionadas }\end{array}$ \\
\hline
\end{tabular}

Dos oito tipos de vegetação cearense (FIGUEIREDO, 1997) apenas cinco são abordadas nos LDs de Biologia analisados, sendo a CLD 3 a que aborda as cinco vegetações, são elas: Caatinga, Cerrado, Mangue, Vegetação Litorânea e Carnaubal. No entanto, não são trazidas informações sobre as vegetações de: Mata Úmida Serrana, Mata Seca e Carrasco (Tabela 1). A Caatinga é o tipo de vegetação caducifólia espinhosa dominante no estado do Ceará e, cuja biota está adaptada ao clima semiárido com temperaturas médias anuais constantes e altas, $26{ }^{\circ} \mathrm{C}$ em média, e precipitação pluviométrica anual inferior a $1000 \mathrm{~mm}$ em média (ARAÚJO, et al., 2005). As vegetações: Mangue, Litorânea e Carnaubal ocorrem em climas mais amenos em virtude da proximidade com o oceano (MORO et al., 2015); e o Cerrado é uma vegetação submetida a um clima seco, mas ocorre em pequenas manchas espalhadas no território cearense (MORO et al., 2015).

As Matas Serranas são consideradas ilhas de umidade que se destacam em meio ao semiárido e estão distribuídas de forma dispersa nos estados do Ceará, Rio Grande do Norte, Paraíba, Pernambuco, Alagoas e Bahia (LOPES et al., 2017). O estado do Ceará contribui com $35 \%$ da área total de florestas serranas em relação aos estados de Pernambuco, Paraíba e Rio Grande do Norte, mas este é um dos estados onde há menos informações documentadas e publicadas (LIMA; MANSANO, 2011). É possível que esse desconhecimento esteja refletido na ausência de informações sobre esse tipo de vegetação nos LDs do ensino básico. Mas apesar da pequena extensão e do pouco conhecimento científico, as serras úmidas nordestinas são importantes devido à presença de florestas sempreverdes e 
semidecíduas em meio a um ambiente dominado pela caatinga decídua, além de serem importantes do ponto de vista ecológico, cultural e socioeconômico (DIOGO et al., 2016; LOPES et al., 2017).

O Carrasco é uma vegetação xerófila arbustiva, ainda pouco conhecida, que ocorre no domínio semiárido do nordeste do Brasil, sobre areias quartzosas profundas, entre 700 e $900 \mathrm{~m}$ de altitude, no planalto da lbiapaba e chapada do Araripe (ARAÚJO; MARTINS, 1999). O Carrasco se difere fisionomicamente da Caatinga pela alta densidade dos indivíduos lenhosos, que possuem troncos finos e pela quase ausência de Cactáceas e Bromeliáceas (ARAÚJO; MARTINS, 1999). Semelhante ao que ocorre com as Matas Úmidas é possível que o Carrasco não seja abordado nos LDs devido à pequena extensão e aos poucos estudos. Além disso, ainda existe uma contradição na literatura se o Carrasco é uma vegetação individualizada (ARAÚJO; MARTINS, 1999) ou se seria um tipo de Caatinga que ocorre em áreas sedimentares (MORO et al., 2015).

TABELA 1. Análise do tema "tipos de vegetação cearense" nas coleções de livros didáticos (CLD) de Biologia, adotadas em 2015 pelas escolas públicas estaduais de Itapipoca-Ceará. Onde: Caatinga $=\mathrm{CA}$, Cerrado $=\mathrm{CER}$, Mangue $=$ MAN, Complexo vegetacional litorâneo $=C V L$ e Mata Ciliar com Carnaubal $=$ MCC; $1=$ fraco, $2=$ regular, $3=$ bom, $4=$ excelente.

\begin{tabular}{|c|c|c|c|c|c|}
\hline \multirow[t]{2}{*}{ Coleção / Vegetação } & \multicolumn{5}{|c|}{ Conteúdo Teórico } \\
\hline & Clareza & Erros & Vocabulário & $\begin{array}{r}\text { Sugestões } \\
\text { atividade }\end{array}$ & Conservação \\
\hline $\begin{array}{l}\text { CLD } 1 \text { (11 pontos) } \\
\text { CA, CER, MAN }\end{array}$ & 3 & 2 & 1 & 3 & 2 \\
\hline $\begin{array}{l}\text { CLD } 2 \text { (14 pontos) } \\
\text { CA, CER, MAN, CVL }\end{array}$ & 3 & 3 & 3 & 2 & 3 \\
\hline $\begin{array}{l}\text { CLD } 3 \text { (16 pontos) } \\
\text { CA, CER, MAN, CVL, } \\
\text { MCC }\end{array}$ & 3 & 3 & 3 & 3 & 4 \\
\hline $\begin{array}{l}\text { CLD } 4 \text { (16 pontos) } \\
\text { CA, CER, MAN, MCC }\end{array}$ & 3 & 3 & 3 & 3 & 4 \\
\hline
\end{tabular}

\begin{tabular}{|c|c|c|c|c|c|}
\hline & Clareza & Qualidade & Legenda & $\begin{array}{r}\text { Relação } \\
\text { com texto }\end{array}$ & Cientificidade \\
\hline $\begin{array}{l}\text { CLD } 1 \text { (11 pontos) } \\
\text { CA, CER, MAN }\end{array}$ & 2 & 3 & 2 & 3 & 1 \\
\hline $\begin{array}{l}\text { CLD } 2 \text { (16 pontos) } \\
\text { CA, CER, MAN, CVL }\end{array}$ & 3 & 3 & 3 & 4 & 3 \\
\hline $\begin{array}{l}\text { CLD } 3 \text { (18 pontos) } \\
\text { CA, CER, MAN, CVL, } \\
\text { MCC }\end{array}$ & 4 & 3 & 4 & 4 & 3 \\
\hline $\begin{array}{l}\text { CLD } 4 \text { (16 pontos) } \\
\text { CA, CER, MAN, MCC }\end{array}$ & 3 & 3 & 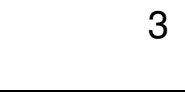 & 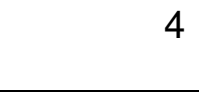 & 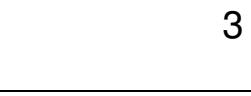 \\
\hline
\end{tabular}

A CLD1 foi à coleção que abordou o menor número de vegetações do Ceará (Tabela 1) e também foi a que destinou um menor número de páginas e de figuras tanto para abordagens diretas quanto indiretas do tema pesquisado (Quadro 1). Esta coleção aborda três dos oito tipos de vegetação cearense: Caatinga, Cerrado e Mangue e contabilizou a menor pontuação na avaliação quantitativa (Tabela 1). O 
volume I ( $\mathrm{VI})$ apresenta o tema em três páginas com o título "Biomas do Brasil", e apresenta um mapa do Brasil, trazendo o estado do Ceará totalmente circunscrito à vegetação de Caatinga. O volume III (VIII) aborda indiretamente assuntos que podem ser utilizados pelo professor para relacionar com as vegetações cearenses.

Ao descrever a Caatinga, o VI da CLD1 a faz em três parágrafos, mencionado alguns animais nativos (cascavel, jiboia, gavião-carcará, gralha, cutia, gambá, preá, veado-catingueiro, tatupeba e ararinha-azul, ave praticamente extinta) sem usar a nomenclatura científica, e, em relação às plantas, citam apenas as cactáceas, sem mencionar exemplo de espécies. O VI traz ainda uma foto de Caatinga arbustiva aberta no período seco, com uma cactácea em primeiro plano e no fundo a vegetação decídua, com a seguinte legenda: "Fotografia da caatinga em São Raimundo Nonato, Pl. Este é o único bioma exclusivamente brasileiro, o que torna sua preservação extremamente importante". Ao abordar a vegetação de Mangue, o VI o faz diretamente em um único parágrafo que contém uma definição cientificamente correta, mas destacando-o como "um ecossistema diferente", sem, contudo explicar o motivo desta diferença e sem pontuar a necessidade de preservação.

O VIII versa sobre "histologia e morfologia das angiospermas", e pode ser utilizado para relacionar com o tema vegetação de mangue quando ilustra as raízes respiratórias (pneumatóforos) e raízes aéreas com fotos de Avicennia schaueriana e Rhizophora mangle. Ao tratar sobre o Cerrado, o VI não menciona que este pode ocorrer no Ceará. Dos estados do nordeste cita apenas Pernambuco e Paraíba e, considera a existência de um único Cerrado, diferente do divulgado por Figueiredo (1997) e Mouro et al. (2015), que reconhecem diversas fitofisionomias de Cerrado. Esta coleção destaca que o solo é propício à agricultura desde que corrigido e fertilizado e, ao invés de destacar a preservação, valoriza o fato de o solo ser propício à agricultura, sem mencionar os prejuízos.

As CLD2 e CLD4 descrevem quatro das oito vegetações cearenses e foram avaliadas de forma semelhante no somatório geral dos critérios, conteúdo teórico e recursos visuais (Tabela 1), A CLD2 se refere às vegetações do Brasil como domínios morfoclimáticos baseado na classificação do geólogo Ab'Saber e a CLD4 utiliza a expressão "Biomas do Brasil". Os VI da CLD2 e VI da CLD4 trazem um mapa do país, representando as regiões e vegetações do Brasil, com a mesma ideia do CLD1, o estado do Ceará totalmente coberto por uma vegetação de Caatinga. Embora o CLD2 utilize os termos domínio da Caatinga, que incluem outras vegetações de menor extensão territorial como as matas serranas e o carrasco, em nenhum momento essas vegetações são citadas como ocorrendo no Ceará.

Os autores do VI da CLD2 explicam que a vegetação da Caatinga é composta por plantas com adaptações marcantes como folhas modificadas em espinhos, revestimentos altamente impermeáveis, caules que armazenam água, etc. e que entre as cactáceas mais expressivas estão o mandacaru e o xique-xique (ambos com seus respectivos nomes científicos). Eles esclarecem que há também arbustos e árvores como mimosas, acácias e amburanas (leguminosas), e entre as poucas espécies que não perdem as folhas destaca-se o juazeiro (também com nome científico), mas apesar de destacar essa variedade de plantas, as duas fotos trazidas para representar a caatinga, mostram somente exemplos de cactáceas.

O VI da CLD4 também descreve as características de clima e adaptações das plantas de forma semelhantes ao da CLD2, mas na CLD4 são citados exemplares da fauna com nomenclatura popular e científica, como os pássaros corrupião, carcará, ararinha azul, além da serpente cascavel. No entanto este volume descreve 
que na estação seca da Caatinga os galhos tornam-se esbranquiçados, o que provavelmente deu origem a seu nome, informação semelhante a da CLD1, o que passa a falsa ideia de que ao perderem as folhas os galhos adquirem a cor branca, sendo que a cor é característica e ao perderem as folhas fica mais evidente.

Em relação ao Cerrado as coleções CLD2 e CLD4 descrevem esse tipo de vegetação, mas não fazem referência a sua ocorrência no território cearense, semelhante ao descrito na CLD1. Mas diferente do CLD1, as CLD2 e CLD4 destacam as diferentes fisionomias do Cerrado, que vão desde formas abertas, como os campos limpos, até formas relativamente densas, florestais, como os cerradões, havendo entre esses dois extremos uma variedade de tipos fisionômicos. A CLD2 menciona ipê, peroba-do-campo e caviúna sem nenhuma referência a fauna, e a CLD4 cita araçá, murici, indaiá, gabiroba, pau-terra e capim-flecha como exemplos da flora além de ema, seriema, tamanduá-bandeira, veado-campeiro e lobo-guará para exemplificar a fauna, mas nenhum deles é acompanhado pelo nome científico. As CLD2 e CLD4 esclarecem também que nem todo vegetal do cerrado possui a característica de troncos tortuosos quando afirmam, por exemplo, que o cerrado possui "vegetação arbórea formada por pequenas árvores e arbustos, muitos deles de troncos retorcidos e cascas espessas (CLD2)" e mencionam as ações antrópicas insustentáveis que desmatam a vegetação nativa e dão lugar a pastagens para criação de gado bovino e culturas agrícolas, Essas coleções também deixam claro que o fogo é um fator ecológico importante, mas esclarecem que quando provocado pela ação humana pode atingir efeitos preocupantes.

O Mangue é definido como um ecossistema que se estende por toda a costa brasileira e embora neste trecho o professor, e até o aluno, compreenda que no Ceará existe manguezal, para os autores da CLD2 o Ceará não aparece na listagem dos estados que possuem mangues. Então cabe ao professor complementar a informação contida no livro. Destaca as espécies de mangue-bravo (Rhizophoda mangle); mangue-manso (Laguncularia racemosa) e espécies do gênero Avicennia, além do caranguejo-do-mangue, as mesmas espécies são abordadas na CLD1, porém traz a importância econômica desta unidade fitoecológica, para a população caiçara. Apesar de destacar que o mangue é uma fonte de alimento para o homem, animais marinhos e aves, esta obra não menciona a necessidade de preservá-lo.

A CLD3 destinou maior número de páginas e figuras tanto para abordagens diretas quanto indiretas (Quadro 1), descreveu o maior número de vegetações do Ceará, cinco das oito: (Caatinga, Cerrado, Mangue, Complexo vegetacional litorâneo, Mata ciliar com carnaubal) e também contabilizou a maior pontuação no somatório geral dos critérios, conteúdo teórico e recursos visuais (Tabela 1). Os autores também utilizam o termo "Bioma" para se referir as vegetações locais, mas apesar disso trazem um mapa do Brasil que mostra a ocorrência de Caatinga e Vegetação litorânea no Ceará, diferente das outras coleções analisadas.

A Caatinga é descrita na CLD3 em seus aspectos climáticos e a relação destes com as fisionomias da vegetação destacando dois períodos: um período seco com vegetação decídua e outro chuvoso onde a vegetação concentra as fenofases de brotamento de folhas, floração e frutificação em um aspecto vivo e vibrante de cores, sons e cheiros. Este aspecto é descrito no trecho do VI da CLD3 que diz "O aspecto árido, desbotado e sem folhas verdes deu nome a esse bioma [...], quando as chuvas retornam, as árvores se cobrem de folhas e a paisagem volta a ficar verde". Essa descrição é importante, pois deixa claro que durante o período de ausência de chuvas a vegetação não morre, ela fica dormente e retoma seu crescimento rapidamente com 0 início das próximas chuvas. A coleção também 
exemplifica com vários espécimes da flora (quipá, mandacaru, facheiro, coroa-defrade, xiquexique, maniçoba, marmeleiro, umbuzeiro, barriguda, ipês, oiticica e juazeiro) e fauna (várias espécies de lagartos, serpentes, quelônios - tartarugas e jabutis, anfíbios, mamíferos - sagui do nordeste, macaco prego, peba, mocó, gambá, caititu, veado-catingueiro, cutia e tatu-bola e aves - carcará, gralha-canção, ema, seriema, a pomba-avoante e galo-de-campina) e, apesar de não citar o nome científico, é relevante o grande número de espécies que é abordado nesta obra.

Além disso, a CLD3 aborda a preocupação com a degradação e a desertificação por meio de práticas insustentáveis como desmatamento e queimadas, e sugere ações de reflorestamento como estratégias de manejo e recuperação de áreas degradadas. É correta a forma como os autores da CLD3 descrevem a Caatinga demonstrando que a vegetação está adaptada ao clima, desmistificando a ideia de que as plantas "sofrem" com a escassez de água. Isto é de extrema importância, pois a mídia costuma associar os eventos naturais de seca, característicos de regiões áridas e semiáridas como o nordeste brasileiro, com tragédias sociais e humanitárias bem como com uma suposta pobreza em termos de biodiversidade, o que não é suportado pela literatura científica (MORO et al., 2014).

O Cerrado na CLD3 é abordado de forma semelhante as CLD2 e CLD4, descrevendo-o em seus aspectos climáticos, florístico, faunístico e de conservação, sem contudo fazer referencia a sua ocorrência no Ceará. O Mangue é descrito de forma semelhante as demais coleções no que diz respeito à flora, e necessidade de preservação, mas na CLD3 apresenta uma maior riqueza de detalhes em relação a fauna, citando que os animais encontrados são "moluscos, vermes poliquetos, crustáceos (camarões, caranguejos, guaiamuns), peixes, aves (gaivotas, garças, socos, maça ricos, urubus, gaviões, flamingos), jacarés e mamíferos, como o guaxinim, que, com o caranguejo chama-maré".

O Complexo Vegetacional Litorâneo é descrito na CLD3, mas não é referido a sua ocorrência no Ceará e o exemplo é relativo ao estado de São Paulo e por isso o livro traz o termo - Restinga para denominar a vegetação litorânea em um parágrafo que expressa: "Além do manguezal, encontramos nas zonas litorâneas a restinga, uma região arenosa com ervas, arbustos e árvores". Após o texto segue uma foto da Vegetação de restinga na Ilha do Cardoso-São Paulo. Apesar de não ser muito texto, o livro aborda o assunto. E se o livro aborda, mesmo que em poucas linhas, o aluno provavelmente irá ler, cabe ao professor a tarefa de buscar outros recursos e complementar ou esclarecer a informação do LD.

A Mata Ciliar com Carnaubal só esta contemplada na CLD3, dentre as CLD de Biologia analisadas. O VII da CLD3 informa também que são extraídas das carnaúbas a cera utilizada em produtos de polir e encerar; suas folhas são também usadas para tecelagem; e os troncos, na construção de moradias. Além disso, os autores chamam a atenção para a preservação dessa unidade fitoecológica, pois afirmam que a mata de cocais é desmatada para as monoculturas, o que afeta o ambiente e as pessoas que dependem da comercialização dos produtos do babaçu e da carnaúba. Corroborando com Moro et al. (2015) quanto a degradação desse tipo vegetacional e necessidade de conservá-lo.

\section{Livros de Geografia}

Do universo de 12 livros de Geografia analisados, apenas cinco abordavam o tema no contexto da vegetação do Ceará. Dos oito tipos de vegetação cearense (FIGUEIREDO, 1997) seis foram abordadas nos livros de Geografia, são: Caatinga, Cerrado, Mangue, Vegetação Litorânea, Mata Ciliar com Carnaubal e Mata Úmida 
Serrana, e apenas o Carrasco e a Mata Seca não estavam pressentes (Tabela 2). Diferiram das CLDs de Biologia, por abordarem a vegetação de Mata Úmida Serrana, e assemelhara-se por não conter informações sobre a Mata Seca e o Carrasco. As CLDs de Geografia analisadas se concentram em caracterizar os aspectos geomorfológicos, pedológicos, hidrológicos e climáticos e destinam pouco espaço para as descrições de fauna e flora.

TABELA 2. Análise do tema "tipos de vegetação" nas coleções de livros didáticos (CLD) de Geografia, adotadas em 2015 pelas escolas públicas estaduais de Itapipoca-Ceará. Onde: Caatinga $=\mathrm{CA}$, Cerrado $=\mathrm{CER}$, Mangue $=$ MAN, Mata Ciliar com Carnaubal $=$ MCC, Mata Seca $=$ MS, Mata Úmidas Serranas $=$ MUS, Vegetação litorânea $=C V L$ e; $1=$ fraco, $2=$ regular, 3 $=$ bom, $4=$ excelente.

\begin{tabular}{|c|c|c|c|c|c|}
\hline \multirow[t]{2}{*}{ Coleção / Vegetação } & \multicolumn{5}{|c|}{ Conteúdo Teórico } \\
\hline & Clareza & Erros & Vocabulário & $\begin{array}{r}\text { Sugestões } \\
\text { atividade }\end{array}$ & Conservação \\
\hline $\begin{array}{l}\text { CLD } 5 \text { (12 pontos) } \\
\text { CA, CER, MAN, MCC }\end{array}$ & 3 & 3 & 2 & 2 & 2 \\
\hline $\begin{array}{l}\text { CLD } 6 \text { (10 pontos) } \\
\text { CA, CER, MUS, MCC }\end{array}$ & 3 & 3 & 3 & 2 & 2 \\
\hline $\begin{array}{l}\text { CLD } 7 \text { (12 pontos) } \\
\text { CA, CER, MUS }\end{array}$ & 3 & 3 & 2 & 2 & 2 \\
\hline \multirow[t]{3}{*}{$\begin{array}{l}\text { CLD } 8 \text { ( } 10 \text { pontos) } \\
\text { CA, CER, MAN, MCC, } \\
\text { CVL }\end{array}$} & 3 & 3 & 2 & 1 & 2 \\
\hline & \multicolumn{5}{|c|}{ Recursos Visuais } \\
\hline & Clareza & Qualidade & Legenda & $\begin{array}{r}\text { Relação } \\
\text { com texto }\end{array}$ & Cientificidade \\
\hline $\begin{array}{l}\text { CLD } 5 \text { (13 pontos) } \\
\text { CA, CER, MAN, MCC }\end{array}$ & 2 & 3 & 3 & 3 & 2 \\
\hline $\begin{array}{l}\text { CLD } 6 \text { (11 pontos) } \\
\text { CA, CER, MUS, MCC }\end{array}$ & 2 & 3 & 2 & 3 & 2 \\
\hline $\begin{array}{l}\text { CLD } 7 \text { (12 pontos) } \\
\text { CA, CER, MUS }\end{array}$ & 2 & 2 & 3 & 3 & 2 \\
\hline $\begin{array}{l}\text { CLD } 8 \text { (11 pontos) } \\
\text { CA, CER, MAN, MCC, } \\
\text { CVL }\end{array}$ & 2 & 3 & 2 & 3 & 2 \\
\hline
\end{tabular}

A CLD5 foi a coleção que destinou o maior número de páginas (13) e o maior número de figuras (17) dentre as coleções de Geografia analisadas (Quadro 1), obteve a maior pontuação (Tabela 2) e tratou das vegetações de Caatinga, Cerrado, Mangue e Mata Ciliar com Carnaubal.

A Caatinga é descrita no $\mathrm{VI}$ desta coleção como sendo "...uma formação exclusivamente brasileira e ocupa aproximadamente $11 \%$ do território em região de clima semiárido, em que estiagens prolongadas ocorrem ciclicamente e proporcionam longos períodos de secas..." No entanto, em outros trechos os autores utilizam o termo Bioma Caatinga. Mas, essa descrição da Caatinga como uma formação exclusivamente brasileira é interessante por fugir daquela comumente utilizada que se refere a Caatinga erroneamente como um Bioma exclusivamente brasileiro. O VI da CLD5 aborda elementos da flora, mas não da fauna e, também 
considera informações sobre os tipos de solo, as ameaças à biodiversidade, incluindo os problemas com a desertificação e a necessidade de preservação das vegetações e dos recursos hídricos. Além disso, os autores também abordam que foram criados vários projetos para tentar erradicar a seca na região. Contudo, afirmam que historicamente, essas verbas são empregadas em propriedades consideradas produtivas, deixando de beneficiar a grande maioria da população. Além disso, a contínua promessa de resolver o problema da seca alimenta as bases de propostas políticas, às vezes fraudulentas, criando o que se convencionou chamar de "indústria da seca". Embora existam tais medidas que de certa forma amenizam a escassez de água na época de secas, no que diz respeito a "resolver o problema da seca ou erradica-la" é uma suposta utopia, visto que as secas ocorrem devido ao clima semiárido do Nordeste. E preciso ter cautela e não associar os eventos de secas naturais com as tragédias sociais e humanitárias.

O Cerrado é descrito na CLD5 com mais detalhes, pois diferente das demais CLD, no VI são citadas diferentes fisionomias do Cerrado e este é divido em cerradão, veredas, campos e morros rochosos e penhascos. Os autores alertam sobre a degradação no cerrado através da agricultura, mineração, e riscos da correção feita por agrotóxicos no solo do cerrado para torná-lo propício a plantação, o que acaba prejudicando o próprio solo e contaminando as águas dos rios e do subsolo.

O Mangue é apresentado como sendo encontrado em toda a costa atlântica Brasileira e são descritos os aspectos ambientais e tipos de espécies, além de ser disponibilizada a letra de uma música para trabalhar a temática. A Mata Ciliar com Carnaubal é descrita sem citar os estados de ocorrência, mas subtende-se que ocorra no Ceará devido afirmar que a mata dos cocais é uma área de transição entre os domínios amazônico e caatinga.

A CLD6 destinou número de páginas e número de figuras semelhantes as demais coleções de Geografia - CLD7 e CLD8, analisadas (Quadro 1), e foram aferidas com pontuações semelhantes no somatório dos critérios conteúdo teórico e recursos didáticos, diferindo apenas nos tipos de vegetação descritos (Tabela 2). A CLD6 abordou as vegetações de Caatinga, Cerrado, Mata Ciliar com Carnaubal, mas a fez com menos detalhamento do que a CLD5, mas por outro lado citou a ocorrência de Mata Úmida Serrana para o nordeste do Brasil, utilizando a denominação de "brejos de altitude".

A CLD7 descreveu as vegetações de Caatinga, Cerrado e Mata Úmida Serrana. A Caatinga e o Cerrado são descritos em seus aspectos ambientais, mas não se faz referência a fauna e flora características desses tipos vegetacionais. Mas em relação a Mata Úmida esta é abordada com mais detalhes do que todas as coleções de Geografia e Biologias analisadas. O VII desta coleção traz um texto complementar que explica a presença da Mata Úmida em meio ao semiárido brasileiro. O texto tem como título "Jardins suspensos no sertão".

No início contextualiza o significado de domínios paisagísticos, e exemplifica com a Mata Atlântica e Caatinga, salientando que estes dois domínios possuem áreas de contato e transição entre seus trechos, chamado por eles de "paisagens de exceção". Essas paisagens de exceção espalham-se por todo o Brasil. Entre elas, destacam-se os enclaves de florestas úmidas do semiárido brasileiro, verdadeiras ilhas de Mata Atlântica em meio à caatinga, que só recentemente têm recebido atenção especial dos cientistas.

Para complementar esta abordagem há a presença de uma imagem de área de floresta úmida na Serra de Baturité, Ceará. A importância das Matas Úmidas 
Serranas é pontuada na literatura científica internacional por Ledru et al. (2007) ao afirmar que as serras úmidas nordestinas, a exemplo da Serra de Baturité, são importantes refúgios para a fauna e flora de florestas tropicais e são por isso locais críticos para permitir que a Mata Atlântica sobreviva em condições climáticas desfavoráveis, oferecendo oportunidade para que este tipo de floresta se expanda em caso de mudança climática futura.

A CLD8 abordou as vegetações de Caatinga, Cerrado, Mangue, Mata Ciliar com Carnaubal, Complexo Vegetacional Litorâneo, e dentre as CLDs de Geografia analisadas foi a que abordou o maior número de vegetações cearenses (Tabela 2). No entanto, o espaço destinado às mesmas foi pequeno e foram abordados os aspectos ambientais e de conservação, mas pouca atenção foi dada as descrições relacionadas à riqueza florística e faunística dessas vegetações. A Caatinga é abordada de forma bastante resumida em apenas um parágrafo, e para o Cerrado são destinados dois parágrafos contemplando a informação das diferentes fisionomias. O Mangue e a Restinga são abordados quando os autores tratam da Vegetação Litorânea. Apesar de ser abordado em poucas linhas, este livro foi o que mais comtemplou sobre a vegetação litorânea.

\section{Prática dos professores}

Foram investigados apenas 19 professores $(68 \%$ do universo amostral pretendido inicialmente), pois dos 14 professores de Biologia, apenas nove responderam ao questionário, e dos 14 de Geografia, apenas 10 concordaram em participar. Em relação ao questionamento sobre "Quais tipos de vegetação do estado do Ceará os professores abordam em suas aulas" foi registrado que dos 19 professores que responderam ao questionário, apenas 11 trabalharam o tema durante o ano de 2015. Foram trabalhados cinco dos oito tipos de vegetação Cearense de Figueiredo (1997) e as mais citadas foram: Caatinga (11), Vegetação Litorânea (6), Mangue (3), Mata Úmida Serrana (3), e Carnaubal (1). Nota-se que os tipos vegetacionais do Ceará abordados nos livros didáticos como vegetações que ocorrem no Ceará (Caatinga, Vegetação Litorânea e Mangue) são os mais ensinados em sala de aula, com destaque para a Caatinga que foi citada por todos os professores. As vegetações de Carrasco, Cerrado e Mata Seca não foram citadas pelos professores como vegetações cearenses que são ensinadas.

Apesar de o Cerrado ser abordado em todas as CLDs analisadas e do detalhamento dispensado na maioria delas o fato de não estar citado sua ocorrência no Ceará deve influenciar para a não abordagem dessa vegetação pelos professores. Nota-se que os professores citam as vegetações geralmente presentes nos LDs que eles utilizam.

Matos e Landim (2014) chamam a atenção para a necessidade de um cuidado ao utilizar os LDs, visto que podem apresentar vários equívocos e omitir muitas informações. Por isso o professor deve refletir sobre o fato de sua prática ser exclusivamente balizada nos LDs. Estes autores salientam ainda que o problema da falta de contextualização nos livros em relação a região nordeste é uma problemática. Este fato foi notório na análise das CLDs de Biologia e Geografia desta pesquisa, pois foram poucos os exemplos que permitem uma relação direta com a vegetação Cearense.

Além disso, as vegetações como a Mata Seca, Mata Úmida, Carnaubal e Mangue ocorrerem no município de Itapipoca, local onde a pesquisa foi realizada, mas a maioria dos professores não aborda essas vegetações em suas aulas. Isso demonstra as dificuldades que os professores têm de ultrapassar os limites do LD no 
planejamento e execução de suas aulas.

Os professores foram indagados também sobre "Quais recursos e estratégias didáticas utilizam" e eles citaram em ordem decrescente de frequência de uso: livro didático, data show, vídeo, resolução de provas de vestibulares e aula de campo, mencionando a dificuldade de realização desta última atividade. O município de Itapipoca e entorno possui características que favorecem as aulas demonstrativas de seis dos oito tipos vegetacionais existentes no estado do Ceará: Caatinga, Mangue, Carnaubal, Mata Seca, Mata Úmida e Vegetação litorânea (ver mapa IPECE, 2007). Além disso, existem áreas que guardam vegetações especiais só mapeáveis em grande escala como os lajedos ricos em registros fósseis e as áreas de vegetação aquática (MORO et al., 2015). Portanto, além dos livros didáticos os professores possuem outros meios que podem utilizar para melhoria de suas aulas, dentre estes a natureza, o mais sofisticado e completo laboratório.

\section{CONCLUSÃO}

Dentre os oito tipos de vegetação cearense, apenas cinco são abordados nos livros de Biologia e seis nos livros de Geografia, adotados pelas escolas públicas estaduais de Itapipoca-Ceará em 2015. Com exceção da Caatinga, as demais vegetações são descritas sem referência clara da sua ocorrência no Ceará. Além disso, os livros de Biologia não abordam as vegetações de Carrasco, Mata Seca e Mata Úmida e os livros de Geografia não descrevem o Carrasco e a Mata Seca. De forma semelhante os professores de Biologia e Geografia, das escolas em que esses LD são utilizados, abordam a vegetação de Caatinga e não trabalham as vegetações de Cerrado, Carrasco e Mata Seca em suas aulas.

O predomínio da abordagem centrada quase que exclusivamente na vegetação de Caatinga tanto nos LDs quanto na prática docente, a despeito da diversidade paisagística do estado do Ceará, pode contribuir para a falsa imagem de que o estado é totalmente ocupado pela Caatinga e que esta seria pobre em riqueza e endemismos de espécies. Pesquisas científicas que abordem a diversidade vegetacional da região nordeste do Brasil em conjunto com a sua abordagem no ensino básico, são estratégias que se realizadas em conjunto podem coadunar para desmitificar os preconceitos relacionados às falsas ideias de pobreza paisagística e de biodiversidade, que são associadas à região nordeste.

\section{REFERÊNCIAS}

ARAÚJO, F. S.; MARTINS, F. R. Fisionomia e organização da vegetação do carrasco no planalto da Ibiapaba, estado do Ceará. Acta Botânica Brasílica, v. 13, n. $1, \quad$ p. $1-13, \quad 1999 . \quad$ Disponível em: <http://www.scielo.br/pdf/abb/v13n1/v13n1a02.pdf>

ARAÚJO, F. S.; RODAL, M. J. N.; BARBOSA, M. J. N.; MARTINS, F. R. Repartição da flora lenhosa no domínio da Caatinga. In: Análise das variações da biodiversidade do bioma Caatinga: suporte a estratégias regionais de conservação. ARAÚJO, F. S.; RODAL, M. J. N; BARBOSA, M. R. V. (org). Ministério do Meio Ambiente, Brasília, p.15-29. 2005.

BARDIN, L. Análise de conteúdo. São Paulo: Edições 70, 2011. 
BEZERRA, G. R.; SUESS, R. C. Abordagem do bioma Cerrado em Livros Didáticos de Biologia do Ensino Médio. Holos, v. 1, p. 233- 242. 2013. Disponível em: $<$ http://dx.doi.org/10.15628/holos.2013.1289>.

BRASIL. Ministério da Educação. Guia de livros didáticos-PNLD 2015. Brasília: MEC/SEB. 2015. Disponível em: <http://www.fnde.gov.br/programas/livrodidatico/guias-do-pnld/item/5940-guia-pnld-2015>.

BRASIL. Resolução no 510, de 07 de abril de 2016. Dispõe sobre as normas aplicáveis a pesquisas em Ciências Humanas e Sociais. Diário Oficial [da] República Federativa do Brasil, Brasília, DF, mai/2016. Disponível em: <Disponível em: http://bit.ly/2fmnKeD>.

DIOGO, I. J. S.; MARTINS, F. R.; VEROLA, C. F.; COSTA, I. R. D. Variation in plantanimal interactions along an elevational gradient of moist forest in a semiarid area of Brazil. Acta Botanica Brasilica, v. 30, n. 1, p. 27-34. 2016. Disponível em: < http://www.scielo.br/pdf/abb/v30n1/0102-3306-abb-30-01-00027.pdf>.

FARIAS, I. M. S.; SILVA, S. P.; NÓBREGA-THERRIEN, S. M.; SALES, J. A. M. Trilhas do labirinto na pesquisa educacional qualitativa: dos procedimentos de coleta de dados ao trabalho de campo. In: FARIAS, I. M. S.; NUNES, J. B. C.; NÓBREGATHERRIEN, S. M. (org.). Pesquisa científica para iniciantes: caminhando no labirinto. Fortaleza: EdUECE, p.67-92. 2010.

FIGUEIREDO, M. A. A cobertura vegetacional do Ceará: Unidades fitoecológicas. In: Ceará. Atlas do Ceará. Edições IPLANCE, Fortaleza. p. 28-29. 1997. Disponível em: <http://www2.ipece.ce.gov.br/atlas/capitulo1/12/125x.htm>.

IBGE - Instituto Brasileiro de Geografia e Estatística. Mapa de biomas do Brasil: primeira aproximação. IBGE, Rio de Janeiro. 2004. Disponível em: < http://www.ibge.gov.br/home/presidencia/noticias/21052004biomashtml.shtm>

IPECE - Instituto de Pesquisa e Estratégia Econômica do Ceará. Ceará em Mapas. 2007. Fortaleza: Governo do Estado do Ceará. Disponível em: <http://www2.ipece.ce.gov.br/atlas/lista/index.htm>.

LEDRU, M. P.; SALATINO, M. L. F.; CECCANTINI, G.; SALATINO, A.; PINHEIRO, F.; PINTAUD, J. C. Regional assessment of the impact of climatic change on the distribution of a tropical conifer in the lowlands of South America. Diversity and Distributions, v. 13, n. 6, p. 761-771, 2007. Disponível em: <DOI: 10.1111/j.14724642.2007.00389.x>

LIMA, J. R.; MANSANO, F. V. A família Leguminosae na Serra de Baturité, Ceará, uma área de Floresta Atlântica no semiárido brasileiro. Rodriguésia, v. 62, n. 3, 2011. Disponível em: < http://www.scielo.br/pdf/rod/v62n3/2175-7860-rod-62-030563.pdf>.

LOPES, S. D. F.; RAMOS, M. B.; ALMEIDA, G. R. D. The Role of Mountains as Refugia for Biodiversity in Brazilian Caatinga: Conservationist Implications. Tropical 
Conservation Science, v. 10, p. 1-12, 2017. Disponível em:< http://journals.sagepub.com/doi/pdf/10.1177/1940082917702651>.

MATOS, A. E. C.; LANDIM, M. O bioma caatinga em livros didáticos de ciências nas escolas públicas do alto sertão sergipano. Alexandria: Revista de Educação em Ciência e Tecnologia, v. 7, n. 2, p. 137-154, 2014. Disponível em: < https://periodicos.ufsc.br/index.php/alexandria/article/view/38219>.

MORO, M. F.; LUGHADHA, E. N.; FILER, D. L.; ARAÚJO, F. S.; MARTINS, F. R. A catalogue of the vascular plants of the Caatinga Phytogeographical Domain: a synthesis of floristic and phytosociological surveys. Phytotaxa, v. 160, n. 1, p. 1-118. 2014. Disponível em:<https://biotaxa.org/Phytotaxa/article/view/phytotaxa.160.1.1>

MORO, M. F.; MACEDO, M. F.; MOURA-FÉ, M. M.; CASTRO, A. S. F.; COSTA, R. C. Vegetação, unidades fitoecológicas e diversidade paisagística do estado do Ceará. Rodriguésia v. 66, n. 3, p. 717-743. 2015. Disponível em: < http://rodriguesia-seer.jbrj.gov.br/index.php/rodriguesia/article/view/1014>.

PRODANOV, C. C.; FREITAS, E. C. Metodologia do trabalho científico: métodos e técnicas da pesquisa e do trabalho acadêmico. 2 ed. Novo Hamburgo: Feevale, 2013. Disponível em: <http://www.faatensino.com.br/wpcontent/uploads/2014/11/2.1-E-book-Metodologia-do-Trabalho-Cientifico-2.pdf>.

SANTOS, N. D.; SILVA, N. F.; OLIVEIRA, T. P. O que ensinamos sobre as primeiras plantas terrestres: análise de livros didáticos do ensino médio. Pesquisas, Botânica, n. 67, p. 321-334, 2015. Disponível em: <http://www.anchietano.unisinos.br/publicacoes/botanica/botanica67/021.pdf>. 